\title{
A single nucleotide polymorphism in the acetyl-coenzyme A acyltransferase 2 (ACAA2) gene is associated with milk yield in Chios sheep
}

\author{
M. Orford, ${ }^{\star}$ G. Hadjipavlou, $†$ O. Tzamaloukas, ${ }^{\star}$ D. Chatziplis,‡ A. Koumas, † A. Mavrogenis, ${ }^{\star}$ \\ C. Papachristoforou, ${ }^{\star}$ and D. Miltiadou ${ }^{\star 1}$ \\ *Department of Agricultural Sciences, Biotechnology and Food Science, Cyprus University of Technology, PO Box 50329, 3603 Limassol, Cyprus \\ †Agricultural Research Institute, PO Box 22016, 1516 Lefkosia, Cyprus \\ ‡Department of Animal Production, School of Agricultural Technology, Alexander Technological Educational Institute of Thessaloniki, PO Box 141, \\ 57400 Sindos, Thessaloniki, Greece
}

\section{ABSTRACT}

The objective of this work was to identify single nucleotide polymorphisms (SNP) in the ovine acetylcoenzyme A acyltransferase 2 (ACAA2) gene and investigate their association with milk production traits. Molecular characterization was accomplished by sequencing the entire coding region and the $3^{\prime}$ and $5^{\prime}$ untranslated regions (UTR) of the $A C A A 2$ gene from individuals of the Chios sheep bred in Cyprus. All exons appeared to be monomorphic except for the last exon, for which a single SNP located in the 3' UTR of the gene (HM537015:g.2982T >C) was detected. Mixed model association analysis, using SNP data from 318 animals from 104 paternal half-sib families and firstlactation phenotype and pedigree information on 2,405 ewes revealed that this SNP was significantly associated with milk yield. The significance of the SNP effect persisted when milk yield information up to the third lactation was analyzed. Both alleles at the locus segregated at similar frequencies. The $\mathrm{T}$ allele was associated with increased milk yield and exhibited partial dominant action. Animals with the g.2982TT or g.2982CT genotype had significantly higher milk yield than those with the g.2982CC genotype, with the g.2982T allele having an additive effect of $13.4( \pm 4.7) \mathrm{kg}$ and a dominance effect of $7.9( \pm 6.1) \mathrm{kg}$. Based on estimated allelic effects and sample allele frequencies, the g.2982T $>$ C SNP explained $10 \%$ of the additive genetic variance for milk yield. A putative mode of action through nutrient metabolism is discussed.

Key words: ACAA2 gene, milk yield, Chios sheep breed, SNP marker

Received July 15, 2011.

Accepted January 27, 2012.

${ }^{1}$ Corresponding author: Despoina.Miltiadou@cut.ac.cy

\section{INTRODUCTION}

The dairy sheep industry plays a vital role in many Mediterranean countries, especially for the production of high quality cheese from local dairy breeds (Carta et al., 2009). Because farmers' income depends on milk yield and total solids that determine cheese yield (Othmane et al., 2002a), an improvement in milk production continues to be the most profitable breeding objective. Increased milk fat and protein contents are also highly desirable from a financial perspective (Ramón et al., 2010). Although classical selection methods, which are commonly used, have provided us with increased farm animal productivity, application of selection schemes encompassing molecular information could expedite improvement in the selection response of breeding animals (Carta et al., 2009).

To date, much attention has been placed on the identification of genetic loci affecting milk production traits in dairy cattle, mainly with the use of specific molecular marker information in experiments aiming at detecting QTL for these traits. These, and subsequent fine-mapping studies, have identified several genes with significant effects on milk-related traits in dairy cattle (http://www.animalgenome.org/cgi-bin/QTLdb/BT/ index). With the advent of new genotyping technologies, high-density genome-wide association studies are being exploited in dairy cattle for detection of nucleotide polymorphisms responsible for previously observed genetic variation in milk performance traits (Jiang et al., 2010; Pryce et al., 2010).

Studies in dairy sheep have used partial and whole genome linkage analyses to map QTL for production traits (Barillet et al., 2005; Gutiérrez-Gil et al., 2009; Raadsma et al., 2009; Mateescu and Thonney, 2010). Given the extended regional diversity of sheep breeds and financial requirements of high-density genotyping and genomic approaches, however, extensive finemapping approaches have been less prevalent in dairy sheep than in dairy cattle. For the identification and characterization of genetic variants associated with 
milk performance traits in various sheep breeds, many research efforts have been based on the candidate gene approach (reviewed in Moioli et al., 2007; Ramos et al., 2009; Staiger et al., 2010).

Recently, Gutiérrez-Gil et al. (2009) detected suggestive QTL for milk, fat, and protein yields on ovine chromosome 23, spanning an orthologous region to the end of bovine chromosome 24 that contains the gene encoding the enzyme acetyl-CoA acyltransferase 2 (ACAA2). The enzyme is involved in lipid metabolism, as it catalyzes the last step in fatty acid $\beta$-oxidation (reviewed in Eaton et al., 1996). Polymorphisms in the gene encoding another enzyme involved in lipid metabolism, that of acyl-CoA:diacylglycerol acyltransferase 1 (DGAT1), have been found to be significantly associated with milk yield or composition in dairy cattle (Grisart et al., 2002; Winter et al., 2002; Näslund et al., 2008). The association of DGAT1 with milk production traits in sheep has also been investigated (Scatà et al., 2009; Garcia Fernández et al., 2011), albeit with conflicting results thus far.

Based on the chromosomal location of $A C A A 2$ in a region where suggestive QTL for milk traits have been mapped (Gutiérrez-Gil et al., 2009) and on its functional role in nutrient metabolism, ACAA2 was regarded as a putative functional and positional candidate gene that may affect milk yield and composition.

The present study aimed at the molecular characterization of the ovine $A C A A 2$ gene and the identification of SNP. Upon identification of a novel SNP in the $3^{\prime}$ untranslated region (UTR) of $A C A A 2$, association analyses were performed on milk performance traits from a Chios sheep population to evaluate and characterize the SNP effects on these traits.

\section{MATERIALS AND METHODS}

\section{Animals and Phenotypic Data}

Data were collected from purebred Chios ewes from the Agricultural Research Institute (ARI) flock (Lefkosia, Cyprus). This flock has been maintained for over 4 decades by ARI, and classical breeding has been applied based on phenotypic selection on milk traits, growth rate (Mavrogenis and Constantinou, 1991), and type of birth (litter size). Mavrogenis (2000) provides information regarding the genetic management of the population, the mating system, as well as the utilization of the ARI nucleus within the breeding strategy of Cyprus. Briefly, mating in the flock is done only via individual hand-matings, following detection of animals in heat, using vasectomized males. Special consideration has been taken to maintain minimum inbreeding. More specifically, males are kept in the flock for mating for only one breeding season, and animals related at least to the second degree (parent-offspring, full-sibs, half-sibs) are not mated with each other. In a recent study, the rate of inbreeding after $42 \mathrm{yr}$ of selection was estimated to be $<0.3 \%$ per generation and close to $5 \%$ for the 19 generations tested [C. Brown (Department of Agricultural Sciences, Biotechnology and Food Science, Cyprus University of Technology, Limassol, Cyprus), M. Orford, and D. Miltiadou, unpublished data].

At the ARI farm, milk yield is recorded according to the regulations of the International Committee for Animal Recording (ICAR; Method A4; ICAR 2011). Along with monthly milk yield measurements, milk samples are obtained and analyzed for fat, protein, and lactose contents and total solids.

For the purpose of the current study, standard records (e.g., date of birth, litter size born, lambing season, lambing year, lambing month, lactation number, age of dam) and phenotypic data on milk traits were collected at the ARI flock for 2,631 purebred Chios ewes from 426 paternal half-sib families, born from 1971 to 2008. The phenotypic data included individual records of total milk yield, fat percentage, and lactation length for first and subsequent lactations (1-7; mean lactation $=2.5$ ). Complete pedigree information was available for all animals with phenotypic records.

\section{DNA Extraction}

Whole blood samples were obtained from 318 ewes, born between 2002 and 2008 at the ARI flock, for subsequent sequencing and genotyping of the ACAA2 gene. Additionally, blood samples were collected from 40 Cyprus fat-tailed ewes from the only commercial flock keeping purebred animals of this breed in Cyprus and from 5 Holstein-Friesian cows. Genomic DNA was isolated from all samples using the Genomic DNA Blood kit (Macherey-Nagel, Düren, Germany), according to the manufacturer's instructions, and DNA quality and quantity were estimated by UV absorption at 260 and $280 \mathrm{~nm}$.

\section{DNA Sequencing}

Each of the exons was PCR amplified from 20 randomly selected Chios ewes using primers and PCR conditions as shown in Table 1. Because few ovine genomic DNA sequences are available in the public domain, bovine exonic sequences were first searched using the BLAST algorithm (AgResearch; http://www.livestockgenomics.csiro.au/blast/) against raw ovine sequence reads held in the International Sheep Genomics Consortium (ISGC) sequence data repository (https://isgcdata.agresearch.co.nz/). Larger contiguous sequences 
were then constructed using the acquired data until the entire ovine exonic sequence (including some flanking intronic sequence) was constructed. The resulting ovine sequences were then realigned to the bovine genome to confirm their correct identification. In all cases, 95.2 to $100 \%$ homology was observed for each exon at the DNA level, depending on the exon. Primers were subsequently designed based on these constructed sequences using the program Primer3 (http://frodo.wi.mit.edu/ primer3/) and used to carefully optimize each PCR reaction to produce clean, high-intensity bands. The PCR reactions were set up in $25-\mu \mathrm{L}$ volumes containing $25 \mathrm{ng}$ of genomic DNA, $0.5 \mathrm{U}$ of Taq DNA polymerase (Qiagen Inc., Valencia, CA), $0.5 \mu M$ concentration of each primer, and 1.5 to $3.5 \mathrm{mM} \mathrm{MgCl}$. After an initial 5-min denaturation step, the PCR reactions were subjected to 30 cycles at $94^{\circ} \mathrm{C}$ for $30 \mathrm{~s}$, the annealing temperatures indicated in Table 1 for $30 \mathrm{~s}, 72^{\circ} \mathrm{C}$ for $30 \mathrm{~s}$, followed by a final elongation step for $5 \mathrm{~min}$ at $72^{\circ} \mathrm{C}$. The reaction products were then resolved on $2 \%$ agarose gels, and the gel-purified excised bands were subjected to direct DNA sequencing from both ends on an ABI 3130 genetic analyzer, using BigDye Terminator v3.1 chemistry (Applied Biosystems, Carlsbad, CA) using the same primers as shown in Table 1 . The resulting sequence data were submitted to GenBank under accession number HM537015.

\section{ACAA2 3' UTR SNP Analysis}

The genetic diversity of the 3 ' UTR was assessed by developing an allele-specific PCR protocol. Primers for detection of the C-allele: ACAA2-F (ATTGAGAACACAGCCTGAGGAGAGC)/ACAA2-C-R (CTTCACCATCCCTTACCCAAACATG) and the T-allele: ACAA2-T-F (ATGCTCTGCACGGAGAGTGCCT)/ ACAA2-R (TGGATTTCAGTTCAG-AAATGCTGCAT) were designed based on the submitted ovine sequence (HM537015). The PCR reactions were con- ducted in $25-\mu \mathrm{L}$ volumes containing $1.5 \mathrm{mM} \mathrm{MgCl}_{2}$, $0.5 \mathrm{U}$ of Taq DNA polymerase (Qiagen Inc.), $25 \mathrm{ng}$ of genomic DNA, and $0.5 \mu M$ concentration of each primer. After an initial 5-min denaturation step, the $\mathrm{PCR}$ reactions were subjected to 35 cycles at $94^{\circ} \mathrm{C}$ for $30 \mathrm{~s}, 66^{\circ} \mathrm{C}$ for $30 \mathrm{~s}, 72^{\circ} \mathrm{C}$ for $30 \mathrm{~s}$, followed by a final elongation step for $5 \mathrm{~min}$ at $72^{\circ} \mathrm{C}$. Reaction products (C allele, $156 \mathrm{bp}$; T allele, $138 \mathrm{bp}$ ) were visualized on $2 \%$ agarose gels stained with SYBR safe DNA gel stain (Invitrogen, Carlsbad, CA).

The allele-specific PCR method developed to genotype the polymorphism identified in the $3^{\prime}$ UTR of the $A C A A 2$ gene was validated by sequencing 46 samples, 26 of which came from the 318 animals included in this study. In addition, 20 unknown randomly selected animals from the largest commercial Chios flock in $\mathrm{Cy}-$ prus were genotyped using our developed allele-specific PCR method and sequencing; complete concordance was observed between the genotyping data obtained by both methods.

\section{Treatment of Phenotypic Data}

Total milk yield, fat percentage, and FCM yield were analyzed without any transformation applied because they were normally distributed. Fat-corrected milk was estimated using the formula FCM $=$ milk $[0.45+$ (0.091 fat)], where milk $=$ total milk yield and fat $=$ fat percentage (Mavrogenis and Papachristoforou, 1988).

Multiple regression and variance component analyses were performed for each of the traits to determine the significant fixed effects for subsequent analyses. Several models with all possible combinations of fixed effects were tested, and the significance of each effect was systematically assessed. Each non-significant effect was removed from the model in a stepwise manner. All fixed-effect models were fitted using the software package R (R Development Core Team, 2006).

Table 1. Primers and reaction conditions for PCR used to amplify ACAA2 exons

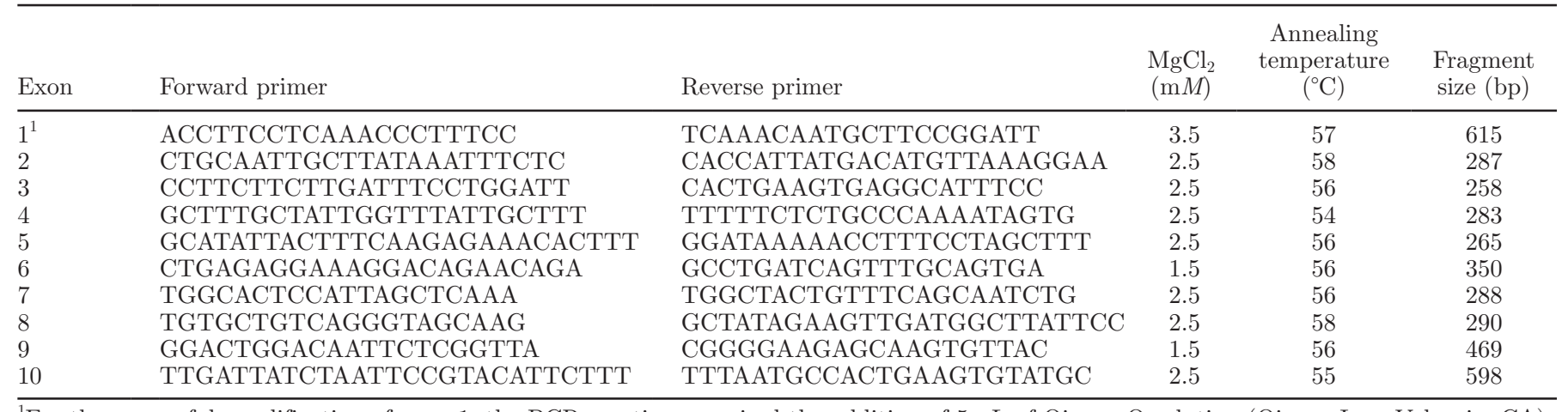

${ }^{1}$ For the successful amplification of exon 1, the PCR reactions required the addition of $5 \mu \mathrm{L}$ of Qiagen Q solution (Qiagen Inc., Valencia, CA). 
The significant fixed effects that were identified for all traits were lambing season (October-November or February-March), lambing year, lactation number, and litter size at birth. The days in milk (lactation length) were fitted as a covariate for each trait.

\section{Mixed Model Association Analysis}

The significant fixed effects and covariates were included in mixed model association analyses to determine the effect of the SNP on all traits (total milk yield, fat percentage, FCM). In addition to the effects described above, the g.2982T $>$ C SNP (3 classes; $1=$ $\mathrm{TT}, 2=\mathrm{TC}, 3=\mathrm{CC}$ ) was fitted as a fixed effect.

Two types of association analyses were performed. In the first analysis, a sire model was fitted using the statistical package R (R Development Core Team, 2006) to analyze the trait data only from the 318 genotyped animals. In the second analysis, an animal model was fitted using ASREML (Gilmour et al., 2006) to analyze all available phenotypic data and pedigree information (1) for first lactation, and (2) for first to third lactations. For phenotype analysis across 3 lactations, multiple records per individual were used, and lactation number was fitted as a fixed effect in the model. For the animal model analysis of multiple lactations, the chosen model included animal (polygenic effects) and permanent animal effects as random effects. Detailed information on animals used, and data analyzed in the 2 separate mixed models is given in Table 2 .

The equations fitted are given as [1] for the sire model and [2] for the animal model:

$$
\begin{aligned}
& \mathbf{y}=\mu+\mathbf{X} \mathbf{b}+\mathbf{Z}_{1} \mathbf{s}+\mathbf{Z}_{2} \mathbf{p}+\mathbf{e} \\
& \mathbf{y}=\mu+\mathbf{X} \mathbf{b}+\mathbf{W} \mathbf{u}+\mathbf{Z}_{2} \mathbf{p}+\mathbf{e} .
\end{aligned}
$$

In both equations, $\mathbf{y}$ is the vector of phenotypes; $\mathbf{b}$ contains the fixed effects and covariates, and $\mathbf{X}$ is its incidence matrix; $\mathbf{s}, \mathbf{u}$, and $\mathbf{p}$ are the vectors of random effects, the sire, polygenic, and permanent animal effects, respectively, mapped onto the data by design matrices $\mathbf{Z}_{1}, \mathbf{W}$, and $\mathbf{Z}_{2}$; and $\mathbf{e}$ is the vector of residuals distributed $N\left(0, \sigma_{e}^{2}\right)$, where $\sigma_{e}^{2}$ is the residual variance. In the sire model, vector $\mathbf{s}$ is of dimension $N_{s}, N_{s}$ being the number of sires in the relationship matrix (i.e., pedigree), whereas in the animal model, vector $\mathbf{u}$ is of dimension $N_{a}$, where $N_{a}$ is the number of animals in the relationship matrix. The permanent animal vector $\mathbf{p}$ and the residual vector e are of dimension $N_{p}$, respectively, where $N_{p}$ is the number of animals with records. The permanent animal effect is only fitted in models analyzing data from lactations 1 to 3 to account for variation due to repeated records per individual.

In all animal model analyses, a fourth class for the ungenotyped animals was included in the SNP effect (i.e., 4 SNP effect classes: $1=\mathrm{TT}, 2=\mathrm{TC}, 3=\mathrm{CC}, 4$ = ungenotyped). Fitting the SNP effect after including a fixed effect with 2 classes $(1=$ genotyped, $2=$ not genotyped) in the model enabled the utilization of all pedigree and phenotypic information to estimate fixed effects and variance components, while assessing the overall significance of the SNP genotype at the ACAA2 locus. The fourth class (ungenotyped animals) within the SNP effect absorbed variation originating from inclusion of records for ungenotyped animals in the analysis, removing any bias in SNP effect assessment.

Heritabilities for total milk yield and FCM yield were estimated from the variance components arising from these mixed model analyses, excluding the SNP effect. In addition, the proportion of phenotypic variance due to permanent animal effect was estimated in the analyses of data from first to third lactation.

\section{Correction for Multiple Testing}

To account for multiple testing, a principal component analysis was conducted on milk yield, fat percentage, and FCM phenotypes across the 3 lactations studied. The principal component analysis results showed that the first 2 principal components explained over $99 \%$ of the variation. Therefore, a Bonferroni correction for multiple testing for 2 effective traits resulted in an adjusted $P$-value of 0.025 for the $5 \%$ significance level.

Table 2. Summary of animals and records used in association analyses of ACAA2 g.2982T $>$ C SNP effects on

\begin{tabular}{|c|c|c|c|c|c|c|c|}
\hline Lactation & Model $^{1}$ & Sire families & Dam families & $\begin{array}{l}\text { Milk } \\
\text { records }\end{array}$ & $\begin{array}{l}\text { Fat } \\
\text { records }\end{array}$ & $\begin{array}{c}\text { FCM } \\
\text { records }\end{array}$ & $\begin{array}{c}\text { Genotype } \\
\text { records }\end{array}$ \\
\hline 1 & Sire & 104 & 226 & 318 & 318 & 318 & 318 \\
\hline 1 to 3 & Sire & 104 & 227 & 717 & 717 & 717 & 318 \\
\hline 1 & Animal & 391 & 1,308 & 2,405 & 2,195 & 2,195 & 318 \\
\hline 1 to 3 & Animal & 410 & 1,374 & 5,793 & 5,348 & 5,348 & 318 \\
\hline
\end{tabular}
milk traits of Chios sheep

${ }^{1}$ Animal model refers to the animal/permanent animal model fitted for records from lactations 1 to 3 . 


\section{Predicted SNP Trait Values and SNP Genotype Effects}

Predicted trait values for each SNP genotype class, including (co)variances for the predictions and standard error of differences (SED) for contrasts, were obtained by utilizing the predict directive in ASREML (Gilmour et al., 2006). Briefly, the predicted trait values are derived from a linear function of the BLUP of the polygenic effect with the best linear unbiased estimate of the significant fixed effects in the model. The predicted trait values were used to estimate additive and dominance SNP effects on traits, and the proportion of additive genetic variance $\left(\mathbf{V}_{\mathbf{A}}\right)$ for each trait accounted for by the SNP. The equations used were as follows:

$$
\begin{gathered}
\text { Additive effect } \mathrm{a}=(\mathrm{TT}-\mathrm{CC}) / 2, \\
\text { Dominance effect } \mathrm{d}=\mathrm{TC}-[(\mathrm{TT}+\mathrm{CC}) / 2] \text {, and } \\
\text { Percentage } \mathrm{V}_{\mathrm{A}} \text { due to } \mathrm{SNP}=100 \\
\times\left\{2 p q[\mathrm{a}+\mathrm{d}(q-p)]^{2}\right\} / \mathrm{V}_{\mathrm{A}},
\end{gathered}
$$

where TT, CC, TC are the predicted trait values for each genotype class; $p$ and $q$ are the allele frequencies at the $\mathrm{SNP}$ locus, and $\mathrm{V}_{\mathrm{A}}$ is the additive genetic variance of the trait obtained from an animal model analysis ignoring the SNP effect. Standard errors of the additive and dominance effects were constructed from the variance-covariance matrix of the predicted genotype classes, as were the SED for pairwise contrasts of the SNP genotype classes.

\section{RESULTS}

In this work, identification of SNP in the $A C A A 2$ gene was performed by sequencing the entire coding region including $3^{\prime}$ and $5^{\prime}$ UTR of the gene from 20 individual Chios sheep. All sequences were submitted to GenBank and can be accessed with accession number HM537015. Alignment of the exonic ovine sequences with their published bovine counterparts demonstrated a high degree of homology, exhibiting between $95 \%$ and $100 \%$ identity, depending on the exon.

Multiple sequence alignment analysis for each exon among individual ovine samples revealed no polymorphisms in the exons tested, except in exon 10. In exon 10, a single $\mathrm{T}$ to $\mathrm{C}$ transition was observed in the $3^{\prime}$ UTR of the gene at a position 114 nucleotides downstream of the termination stop codon (position 199 from the start of the exon). The $\mathrm{C}$ allele was observed at a relatively high frequency $(32 \%)$ in the 20 animals screened originally, and thus the g.2982T $>$ C

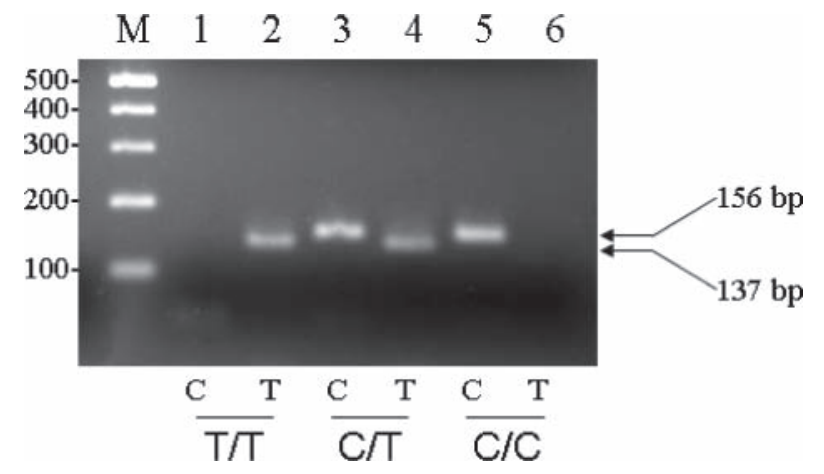

Figure 1. Genotyping of the HM537015:g.2982T $>$ C polymorphism within the $3^{\prime}$ untranslated region (UTR) of the $A C A A 2$ gene. Allelespecific genotyping of homozygous TT, heterozygous CT, and homozygous CC animals (from left to right).

polymorphism merited further investigation. Therefore, an allele-specific PCR assay was utilized to screen DNA samples from 318 Chios sheep (Figure 1). In addition, 40 Cyprus fat-tailed sheep were genotyped to investigate if the identified SNP is breed-specific. Within the Chios sheep population, frequencies were 0.44 and 0.56 for the $\mathrm{C}$ and $\mathrm{T}$ alleles, respectively, with approximately half of the animals (162) showing a heterozygous genotype and one-third (96) having a T/T homozygous genotype. Allele frequencies in the sample of 40 Cyprus fat-tailed sheep were 0.38 and 0.62 for the $\mathrm{C}$ and $\mathrm{T}$ alleles, respectively. Genotype frequencies were found to be in Hardy-Weinberg equilibrium in both the Chios and the Cyprus fat-tailed sheep populations.

The mean $( \pm \mathrm{SD})$ for milk yield, fat percentage, and FCM yield for all Chios animals with phenotypes is given in Table 3. For the 318 genotyped ewes, the respective first-lactation means $( \pm \mathrm{SD})$ were $211( \pm 53)$ $\mathrm{kg}, 4.6( \pm 0.49) \%$, and $182( \pm 44) \mathrm{kg}$, and mean lactation length was $154( \pm 23)$ d.

The heritability for milk yield and FCM was estimated, across all animals with phenotypes, to be 0.35 \pm 0.04 and $0.33 \pm 0.04$, respectively, for first lactation, and $0.24 \pm 0.02$ and $0.22 \pm 0.02$, respectively, for lactations 1 to 3 . For the analysis of first to third lactation records, the proportion of both milk yield and FCM phenotypic variance due to permanent animal effect was found to be $0.10 \pm 0.02$. Heritability estimates generally agreed with previous calculations of milk yield heritability in the ARI flock (Mavrogenis, 1982; Mavrogenis and Papachristoforou, 1988; Chatziplis et al., 2012), in other Chios sheep populations (Ligda et al., 2000) and other sheep breeds (Othmane et al., 2002b).

Mixed model association analysis of the g.2982T $>$ C SNP was performed for total milk yield, FCM, and fat percentage at first lactation and across lactations 1 to 3 . None of the analyses showed a significant as- 
Table 3. Trait means, ranges, and phenotypic standard deviations for all animals with milk trait records

\begin{tabular}{llcrc}
\hline Trait & Analysis & Mean & Range & $\mathrm{SD}^{1}$ \\
\hline Milk yield $(\mathrm{kg})$ & Lactation 1 & 179.7 & $12.0-639$ & 44.8 \\
FCM $(\mathrm{kg})$ & Lactation 1 to 3 & 218.5 & $8.0-750$ & 50.6 \\
\multirow{2}{*}{ Fat percentage } & Lactation 1 & 165.5 & $11.0-578$ & 40.0 \\
& Lactation 1 to 3 & 211.3 & $11.0-733$ & 47.0 \\
& Lactation 1 & 5.01 & $2.3-8.8$ & 0.60 \\
\hline
\end{tabular}

${ }^{1}$ Phenotypic standard deviations after adjusting for fixed effects.

${ }^{2}$ Descriptive statistics across the 3 lactations.

sociation of the SNP genotype with fat percentage. Sire model analysis of data from the 318 genotyped animals resulted in significant SNP effects obtained for total milk yield $(P<0.002)$ and FCM $(P<0.002)$ at first lactation (Table 4).

When the complete data set was used, and an animal model was fitted, the overall SNP genotype effects on total milk yield and FCM persisted, both when first lactation and first to third lactation phenotypes were analyzed (Table 4). The g.2982T $>$ C SNP effect was found to be strongest for first lactation and somewhat diluted when analyzing data from first to third lactation (Table 4). Even so, with multiple testing corrections, the significance of the g.2982T $>$ C SNP effect on milk yield remained, both for first lactation $(P<0.004)$ and first to third lactation $(P<0.025)$. After correction for multiple testing, the g.2982T $>$ C SNP effect on FCM remained significant only for the first lactation (Table 4).

The significance of pairwise contrasts between the predicted trait values of the 3 genotype classes was determined using a 2-sample $t$-test (Table 4). Significant differences were found for both milk yield and FCM between the $\mathrm{CC}$ and TT, and the $\mathrm{CC}$ and $\mathrm{CT}$ genotype pairs at the g.2982T >C SNP locus, but not between TT and CT.

Estimations using the predicted trait values for each SNP genotype class showed that the g.2982T allele had an additive effect of $13.4( \pm 4.7) \mathrm{kg}$ on first-lactation milk yield and of $11.1( \pm 4.1) \mathrm{kg}$ on first-lactation FCM (Table 5). The dominance effect of the $\mathrm{T}$ allele at the locus was $7.9( \pm 6.1) \mathrm{kg}$ for milk yield and $7.8( \pm 5.4)$ $\mathrm{kg}$ for FCM (Table 5). These results suggest a partial dominance effect of the $\mathrm{T}$ allele at the locus. Based on the estimated allelic effects and the allele frequencies observed in the sample, we estimated that the g.2982T $>$ C SNP genotype explained $10 \%$ of the additive genetic variance for first-lactation milk yield and $11 \%$ for first-lactation FCM (Table 5).

\section{DISCUSSION}

The present work provides evidence that a novel SNP in the $3^{\prime}$ UTR of the ACAA2 gene is associated with milk yield in Chios sheep. In particular, the HM537015:g.2982T>C SNP, located 114 nucleo-

Table 4. Test statistics for overall g.2982T $>$ C SNP effect on milk production traits, using sire and animal models, along with genotype means and significance of genotype contrasts for each trait using the animal model

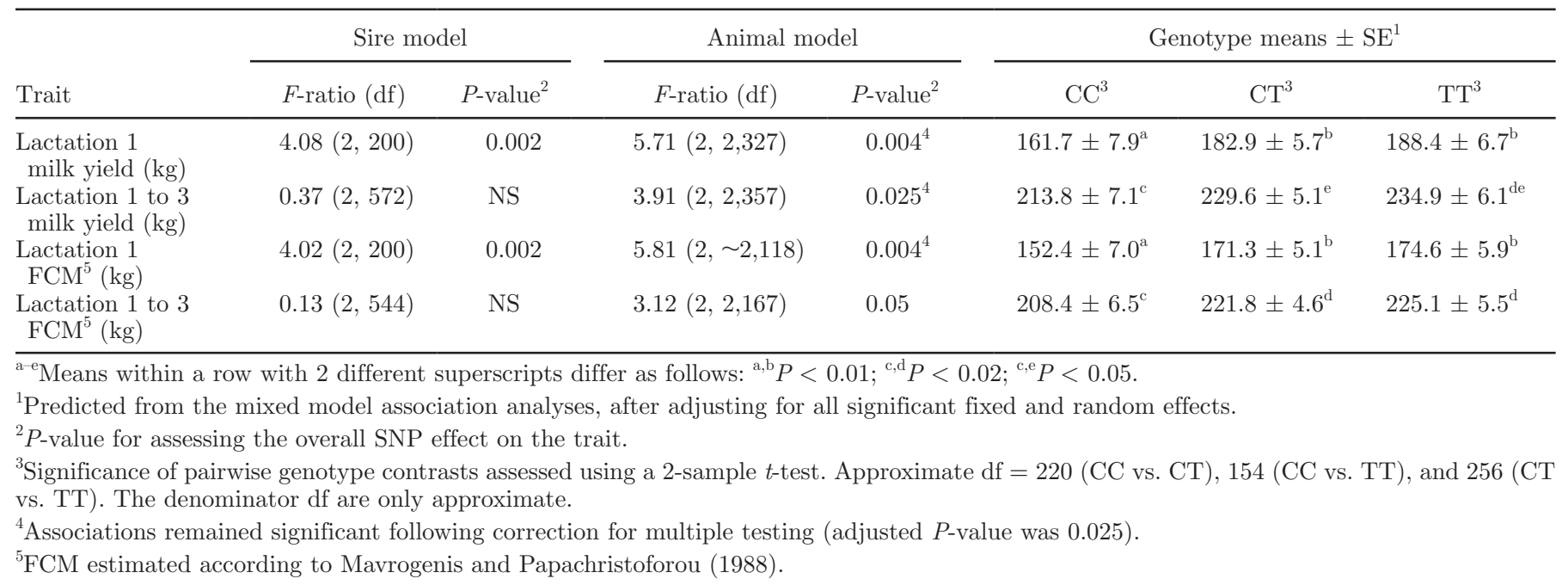


Table 5. Single nucleotide polymorphism allelic effects and percentage of additive genetic variance explained by g.2982T >C SNP locus genotypes

\begin{tabular}{|c|c|c|c|}
\hline Trait & $\mathrm{a}^{1} \pm \mathrm{SE}$ & $\mathrm{d}^{2} \pm \mathrm{SE}$ & $\begin{array}{l}\text { Genetic variance } \\
\text { due to } \operatorname{SNP}^{3}(\%)\end{array}$ \\
\hline Lactation 1 milk yield (kg) & $13.4 \pm 4.7$ & $7.9 \pm 6.1$ & 10 \\
\hline Lactation 1 to 3 milk yield $(\mathrm{kg})$ & $10.6 \pm 4.25$ & $5.3 \pm 5.6$ & 7 \\
\hline Lactation $1 \mathrm{FCM}^{4}(\mathrm{~kg})$ & $11.1 \pm 4.1$ & $7.8 \pm 5.4$ & 11 \\
\hline Lactation 1 to $3 \mathrm{FCM}^{4}(\mathrm{~kg})$ & $8.3 \pm 3.9$ & $5.1 \pm 5.1$ & 6 \\
\hline
\end{tabular}

tides downstream of the termination stop codon of the ACAA2 gene, was significantly associated with total milk yield and FCM yield. Based on predicted g.2982T >C SNP genotype values from mixed model association analyses, Chios ewes with a CC homozygous genotype were found to produce significantly less milk than heterozygous $\mathrm{CT}$ animals, with the latter having increased milk yield by approximately $11 \%(161.7 \pm 7.9$ $\mathrm{kg}$ vs. $182.9 \pm 5.7 \mathrm{~kg} ; P<0.01)$. Although the addition of a further $\mathrm{T}$ allele tended to increase milk yield, it did not significantly improve milk output, suggesting a putative partial dominant effect of the $\mathrm{T}$ allele on the trait. Genotypic frequencies at the g.2982T $>$ C position were in Hardy-Weinberg equilibrium in the Chios sheep, even though the Chios flock at ARI has been under selection for milk traits since the late 1980s. The selection indices used at ARI combine individual capacity of young stock for growth and milk production of female ancestors (Mavrogenis and Constantinou, 1991). Strong selection is also made based on type of birth (litter size born) by removing singletons from the flock even if they have a high selection index for milk yield and growth rate.

Because of the magnitude of the identified allelic substitution effect on milk yield, we anticipate that heterozygous CT or homozygous TT ewes would exhibit particularly favorable selection indices for milk production. Therefore, the favorable $\mathrm{T}$ allele at the locus would be expected to have increased in frequency compared with the $\mathrm{C}$ allele, or even become fixed in the selected flock. The near-equal frequencies of the 2 alleles in the Chios sheep population after $30 \mathrm{yr}$ of phenotypic selection may have arisen from a low frequency of the $\mathrm{T}$ allele in the initially established flock. Or, it might be a consequence of unfavorable pleiotropic effects of the SNP, or of a tightly linked variant, on other traits under selection, such as survival, fecundity, or growth rate. Negative genetic correlations between milk production and reproductive traits have been reported in many studies, mainly in dairy cattle (Pryce et al., 2010).
A recent major gene detection study that included a segregation analysis of the same population showed that a high probability exists for a major gene for milk yield to be segregating within the ARI Chios sheep population, but also within another population of the same breed in Greece (Chatziplis et al., 2012). These findings support the substantial effect of the g.2982T > C SNP on milk yield detected in this study. Although the current study provides evidence that the g.2982T $>$ C SNP is significantly associated with milk yield, it remains to be shown whether the identified SNP is the causative mutation affecting milk yield. The observed SNP effects may be due to other causative polymorphisms within the noncoding region of the gene or within a tightly linked gene. In Churra ewes, a suggestive QTL for milk yield was mapped in a region of ovine chromosome 23 where the $A C A A 2$ gene is located (Gutiérrez-Gil et al., 2009). Close examination of the sheep genome version 2 (http://sheephapmap.org/ news/Data_Access_OARv2p0.php) revealed, within the region between markers MCM136 and URB031 harboring the QTL and the $A C A A 2$ gene, the $L I P G$ gene, which encodes the enzyme endothelial lipase. Thus, LIPG could be another obvious candidate gene. Preliminary results, however, showed no significant association between polymorphisms identified within the entire $L I P G$ coding region or the $5^{\prime}$ and $3^{\prime}$ UTR and milk yield (unpublished data).

The possibility that the $A C A A 2$ gene may well be the locus affecting increased milk yield should be investigated further, particularly because of the functional role of the enzyme acetyl-CoA acyltransferase 2 (mitochondrial 3-ketoacyl-CoA thiolase), encoded by this gene. The enzyme catalyzes the final step of the mammalian mitochondrial fatty acid $\beta$-oxidation (reviewed in Eaton et al., 1996). Other lipid metabolizing enzymes such as acyl-CoA:diacylglycerol acyltransferase 1 (DGAT1) have been found to be associated with milk production traits in dairy cattle (Grisart et al., 2002; Winter et al., 2002; Näslund et al., 2008) and sheep (Scatà et al., 
2009). In addition, several other enzymes involved in fat metabolism have been investigated and associated with milk production traits (reviewed in Moioli et al., 2007).

Gluconeogenesis is usually increased 2- to 3-fold during early lactation to meet the demands of the mammary gland for lactose synthesis (reviewed in Drackley et al., 2001; Vernon, 2005). The increased energy needs of the liver for gluconeogenesis are met primarily by increased fatty acid oxidation, leading to an increase in acetyl CoA. Because $A C A A 2$ catalyzes the last step in fatty acid $\beta$-oxidation leading to the production of acetyl CoA units, future studies could be directed toward a detailed assessment of the effect of the $A C A A 2$ $2982 \mathrm{~T}>\mathrm{C}$ polymorphism on its level of expression and subsequent activity.

Examination of the entire coding region of the $A C A A 2$ gene in 20 individuals did not reveal any SNP, suggesting that a nonsynonymous polymorphism that could directly disrupt the function of the mature protein is very rare, with a frequency $<0.05$. The only $A C A A 2 \mathrm{SNP}$ detected was located in exon 10 within the $3^{\prime}$ UTR of the gene. Examination of exon 10 in several different species revealed a high degree of homology, particularly between sheep, cow, and horse. The degree of homology is lower when examining the entire exon of more diverse species. However, even for diverse species, the nucleotides located around position 199 from the start of the exon appear to be highly conserved with the $\mathrm{T}$ nucleotide residing at position 199. Available data from Genbank and expressed sequence tag (EST) databases show that in over 100 EST bovine entries, no C allele is present, in agreement with 5 Holstein-Friesian cows analyzed in this study that were all TT homozygous. These findings suggest either that the $\mathrm{T}$ allele has become fixed in dairy cattle or that the mutation at this locus was generated after the divergence of the cattle and sheep species.

The association observed between the SNP identified in the $3^{\prime}$ UTR of the $A C A A 2$ gene requires further investigation by functional studies to determine whether this mutation affects the expression of the enzyme. At present, evidence is mounting that regulation of mRNA processing and stability is controlled by the flanking $5^{\prime}$ and 3' UTR (Pesole et al., 2001). Several roles in gene expression have been attributed to the UTR, including mRNA export and stability, cytoplasmic localization and translation efficiency. Polymorphisms detected in the UTR of the myostatin gene $(G D F 8)$ were shown to affect muscularity in sheep (Clop et al., 2006). The GDF8 g +6723G $>$ A mutation, associated with increased muscle depth in Texel (Clop et al., 2006) and Charollais sheep (Hadjipavlou et al., 2008), was shown to create an illegitimate target site for the microRNA (miRNA) sequences miR-1 and miR0206 in the $3^{\prime}$ UTR, resulting in translational repression and therefore decreased levels of myostatin protein (Clop et al., 2006).

When the region harboring the $A C A A 2$ polymorphism was analyzed using the online MicroInspector program (http://bioinfo.uni-plovdiv.bg/microinspector), differences were apparent between the 2 alleles, with respect to potential miRNA binding sites. More specifically, in silico analysis showed that the presence of a $\mathrm{C}$ at position 199 from the start of the exon (g.2982C allele) caused loss of a bta-miR-197 binding site, but additionally created new binding sites for bta-miR-2461 5p and bta-miR-490. The observed C to $\mathrm{T}$ transition at this position may therefore result in alternative stability or regulation of the ACAA2 mRNA processing. However, experimental evidence is required to validate this hypothesis.

\section{CONCLUSIONS}

To the best of our knowledge, this is the first study reporting a significant association between a polymorphism within the $A C A A 2$ gene and a milk production trait in ruminants. Further associations and functional studies are necessary to further investigate this finding. The g.2982T $>\mathrm{C}$ polymorphism could be used as a marker to examine whether it exhibits similar effects on milk production traits in other ovine breeds. Future work should also be directed toward a more thorough evaluation of the g. $2982 \mathrm{~T}>\mathrm{C}$ polymorphism and its pleiotropic effects on other traits, before it could be considered for use in marker-assisted selection in dairy sheep.

\section{ACKNOWLEDGMENTS}

This work was funded by the Cyprus Research Promotion Foundation and the Cyprus University of Technology. We thank the technical staff of the Animal Production section at the Agricultural Research Institute (Lefkosia, Cyprus) for the management of the Chios sheep flock through the years. We also thank L. Bunger (Scottish Agricultural College, University of Edinburgh, UK) and two anonymous reviewers for valuable discussion and suggestions on an earlier version of the manuscript.

\section{REFERENCES}

Ramón, M., A. Legarra, E. Ugarte, J. J. Garde, and M. D. PérezGuzmán. 2010. Economic weights for major milk constituents of Manchega dairy ewes. J. Dairy Sci. 93:3303-3309.

Barillet, F., J. J. Arranz, and A. Carta. 2005. Mapping quantitative trait loci for milk production and genetic polymorphisms of milk proteins in dairy sheep. Genet. Sel. Evol. 37(Suppl. 1):S109-S123. 
Carta, A., S. Casu, and S. Salaris. 2009. Invited review: Current state of genetic improvement in dairy sheep. J. Dairy Sci. 92:58145833 .

Chatziplis, D. G., O. Tzamaloukas, D. Miltiadou, C. Ligda, A. Koumas, A. P. Mavrogenis, A. Georgoudis, and C. Papachristoforou. 2012. Evidence of major gene(s) affecting milk traits in Chios sheep breed. Small Rumin. Res. http://dx.doi.org/10.1016/j. smallrumres.2011.12.009.

Clop, A., F. Marcq, H. Takeda, D. Pirottin, X. Tordoir, B. Bibe, J. Bouix, F. Caiment, J. M. Elsen, F. Eychenne, C. Larzul, E. Laville, F. Meish, D. Milenkovic, J. Tobin, C. Charlier, and M. Georges. 2006. A mutation creating a potential illegitimate microRNA target site in the myostatin gene affects muscularity in sheep. Nat. Genet. 38:813-818

Drackley, J. K., T. R. Overton, and G. N. Douglas. 2001. Adaptations of glucose and long-chain fatty acid metabolism in liver of dairy cows during the periparturient period. J. Dairy Sci. 84(E. Suppl.):E100-E112.

Eaton, S., K. Bartlett, and M. Pourfarzam. 1996. Mammalian mitochondrial $\beta$-oxidation. Biochem. J. 320:345-357.

Garcia Fernández, M., B. Gutiérrez-Gil, J. P. Sanchez, J. A. Moran, E. Garcia Gamez, L. Alvarez, and J. J. Arranz. 2011. The role of bovine causal genes underlying dairy traits in Spanish Churra sheep. Anim. Genet. 42:415-420.

Gilmour, A. R., B. J. Gogel, B. R. Cullis, and R. Thompson. 2006. ASReml User Guide. Release 2.0 VSN International Ltd., Hemel Hempstead, UK.

Grisart, B., W. Coppieters, F. Farnir, L. Karim, C. Ford, P. Berzi, N. Cambisano, M. Mni, S. Reid, P. Simon, R. Spelman, M. Georges, and R. Snell. 2002. Positional candidate cloning of a QTL in dairy cattle: identification of a missense mutation in the bovine DGAT1 gene with major effect on milk yield and composition. Genome Res. 12:222-231.

Gutiérrez-Gil, B., M. F. El-Zarei, L. Alvarez, Y. Bayón, L. F. de la Fuente, F. San Primitivo, and J. J. Arranz. 2009. Quantitative trait loci underlying milk production traits in sheep. Anim. Genet. 40:423-434

Hadjipavlou, G., O. Matika, A. Clop, and S. C. Bishop. 2008. Two single nucleotide polymorphisms in the myostatin $(G D F 8)$ gene have significant association with muscle depth of commercial Charollais sheep. Anim. Genet. 39:346-353.

ICAR. 2011. International Agreement of Recording Practices. Guidelines approved by the General Assembly held in Riga, Latvia on June 2010. Section 2.2:57-67. International Committee of Animal Recording, Rome, Italy.

Jiang, L., J. Liu, D. Sun, P. Ma, X. Ding, Y. Yu, and Q. Zhanf. 2010. Genome wide association studies for milk production traits in Chinese Holstein population. PLoS ONE 5:e13661.

Ligda, C., G. Gabriilidis, T. Papadopoulos, and A. Georgoudis. 2000. Estimation of genetic parameters for production traits of Chios sheep using a multitrait animal model. Livest. Prod. Sci. 66:217221

Mateescu, R. G., and M. L. Thonney. 2010. Genetic mapping of quantitative trait loci for milk production in sheep. Anim. Genet. 41:460-466.

Mavrogenis, A. P. 1982. Environmental and genetic factors influencing milk production and lamb output of Chios sheep. Livest. Prod. Sci. 8:519-527.

Mavrogenis, A. P. 2000. Analysis of genetic improvement objectives for sheep in Cyprus. Opt. Médit. A Sem. Medit. 43 :33-36.
Mavrogenis, A. P., and A. Constantinou. 1991. Selection index and expected genetic progress in Chios sheep. Technical Bulletin 131, Agricultural Research Institute, Ministry of Agriculture and Natural Resources, Lefkosia, Cyprus.

Mavrogenis, A. P., and C. Papachristoforou. 1988. Estimation of the energy value of milk and prediction of fat-corrected milk yield in sheep and goats. Small Rumin. Res. 1:229-236.

Moioli, B., M. D'Andrea, and F. Pilla. 2007. Candidate genes affecting sheep and goat milk quality. Small Rumin. Res. 68:179-192.

Näslund, J., W. F. Fikse, G. R. Pielberg, and A. Lundén. 2008. Frequency and effect of the bovine acyl-CoA:diacylglycerol acyltransferase 1 (DGAT1) K232A polymorphism in Swedish dairy cattle. J. Dairy Sci. 91:2127-2134.

Othmane, M. H., J. A. Carriedo, L. F. de la Fuente Crespo, and F. San Primitivo. 2002a. An individual laboratory cheese-making method for selection in dairy ewes. Small Rumin. Res. 45:67-73.

Othmane, M. H., J. A. Carriedo, F. San Primitivo, and L. F. de la Fuente. 2002b. Genetic parameters for lactation traits of milking ewes: Protein content and composition, fat, somatic cells and individual laboratory cheese yield. Genet. Sel. Evol. 34:581-596.

Pesole, G., F. Mignone, C. Gissi, G. Grillo, F. Licciulli, and S. Liuni. 2001. Structural and functional features of eukaryotic mRNA untranslated regions. Gene 276:73-81.

Pryce, J. E., S. Bolormaa, A. J. Chamberlain, P. J. Bowman, K. Savin, M. E. Goddard, and B. J. Hayes. 2010. A validated genome-wide association study in 2 dairy cattle breeds for milk production and fertility traits using variable length haplotypes. J. Dairy Sci. 93:3331-3345.

R Development Core Team. 2006. R: A language and environment for statistical computing. R Foundation for Statistical Computing, Vienna, Austria. http://www.R-project.org.

Raadsma, H. W., E. Jonas, D. McGill, M. Hobbs, M. K. Lam, and P. C. Thomson. 2009. Mapping quantitative trait loci (QTL) in sheep. II. Meta-assembly and identification of novel QTL for milk production traits in sheep. Genet. Sel. Evol. 41:45.

Ramón, M., A. Legarra, E. Ugarte, J. J. Garde, and M. D. PérezGuzmán. 2010. Economic weights for major milk constituents of Manchega dairy ewes. J. Dairy Sci. 93:3303-3309.

Ramos, A. M., C. A. P. Matos, P. A. Russo-Almeida, C. M. V. Bettencourt, J. Matos, A. Martins, C. Pinheiro, and T. Rangel-Figueiredo. 2009. Candidate genes for milk production traits in Portuguese dairy sheep. Small Rumin. Res. 82:117-121.

Scatà, M. C., F. Napolitano, S. Casu, A. Carta, G. De Matteis, F. Signorelli, G. Annicchiarico, G. Catillo, and B. Moioli. 2009. Ovine acyl CoA:diacylglycerol acyltransferase 1-Molecular characterization, polymorphisms and association with milk traits. Anim. Genet. 40:737-742.

Staiger, E. A., M. L. Thonney, J. W. Buchanan, E. R. Rogers, P. A. Oltenacu, and R. G. Mateescu. 2010. Effect of prolactin, $\beta$-lactoglobulin, and $\kappa$-casein genotype on milk yield in East Friesian sheep. J. Dairy Sci. 93:1736-1742.

Vernon, R. G. 2005. Lipid metabolism during lactation: A review of adipose tissue-liver interactions and the development of fatty liver. J. Dairy Res. 72:460-469.

Winter, A., W. Kramer, F. A. Werner, S. Kollers, S. Kata, G. Durstewitz, J. Buitkamp, J. E. Womack, G. Thaller, and R. Fries. 2002. Association of a lysine-232/alanine polymorphism in a bovine gene encoding acyl-CoA:diacylglycerol acyltransferase (DGAT1) with variation at a quantitative trait locus for milk fat content. Proc. Natl. Acad. Sci. USA 99:9300-9305. 